\title{
Wide-band low-noise distributed front-end for multi-gigabit CPFSK receivers
}

\author{
Petersen, Anders Kongstad; Ebskamp, F; Pedersen, Rune Johan Skullerud; Zhang, Xiupu
}

Published in:

I E E E - M T T S International Microwave Symposium. Digest

Link to article, DOI:

10.1109/MWSYM.1994.335155

Publication date:

1994

Document Version

Publisher's PDF, also known as Version of record

Link back to DTU Orbit

Citation (APA):

Petersen, A. K., Ebskamp, F., Pedersen, R. J. S., \& Zhang, X. (1994). Wide-band low-noise distributed front-end for multi-gigabit CPFSK receivers. I E E E - M T T S International Microwave Symposium. Digest, 3, $1375-1378$. https://doi.org/10.1109/MWSYM.1994.335155

\section{General rights}

Copyright and moral rights for the publications made accessible in the public portal are retained by the authors and/or other copyright owners and it is a condition of accessing publications that users recognise and abide by the legal requirements associated with these rights.

- Users may download and print one copy of any publication from the public portal for the purpose of private study or research.

- You may not further distribute the material or use it for any profit-making activity or commercial gain

- You may freely distribute the URL identifying the publication in the public portal 


\title{
TH1D-1
}

\section{WIDE-BAND LOW-NOISE DISTRIBUTED FRONT-END FOR MULTI-GIGABIT CPFSK RECEIVERS}

\author{
A. K. Petersen ${ }^{\dagger}$, F. Ebskamp, R. J. S. Pedersen and X. Zhang \\ Center for Broadband Telecommunications, Electromagnetics Institute \\ Technical University of Denmark, Build. 348, DK-2800, Lyngby, Denmark \\ $\dagger$ Presently withUniversity of California at Santa Barbara, \\ Dept. of Electrical and Computer Engineering, Santa Barbara, CA 93106, USA
}

\begin{abstract}
In this paper a distributed optical front-end amplifier for a coherent optical CPFSK receiver is presented. The measured average input noise current density is $20 \mathrm{pA} / \sqrt{\mathrm{Hz}}$ in a 3-13 GHz bandwidth. This is the lowest value reported for a distributed optical front-end in this frequency range. The front-end is tested in a system set-up at a bit rate of $2.5 \mathrm{Gbit} / \mathrm{s}$ and a receiver sensitivity of $-41.5 \mathrm{dBm}$ is achieved at a $10^{-9}$ bit error rate.
\end{abstract}

\section{INTRODUCTION}

Coherent optical heterodyne receivers have been demonstrated both in laboratories [1] and field trials [2]. Due to the relatively high complexity of the coherent receiver a monolithic realisation would be required for operational applications. A receiver for the commonly used modulation scheme, CPFSK (Continuous Phase Frequency Shift Keying), is shown in fig. 1 . The receiver normally operates at an IF (Intermediate Frequency) 2-4 times the bit rate with a bandwidth approximately twice the bit rate. In order to obtain

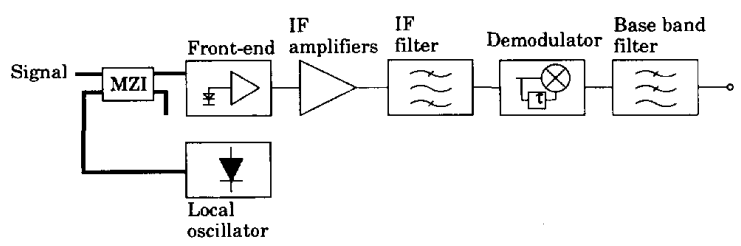

Fig. 1 CPFSK system set-up with Mach-Zehnder Interferometer (MZI). a high receiver sensitivity using a moderate local oscillator power a wide-band low-noise front-end in the receiver is required.

Different tuned circuit topologies have been suggested [3,4], but these topologies are difficult to implement as monolithic circuits due to their poor stability properties. Another circuit topology, which has not been investigated very much, is the distributed optical front-end amplifier [5,6] as shown in fig. 2. In this front-end the junction capacitance of the photodiode and the bond wire between the photodiode and the MMIC $\left(\lg _{\mathrm{g} 1}\right)$ are incorporated in an artificial gate transmission line [6]. On-chip the artificial gate transmission line consists of the gate-source capacitances of the FETs and the inductances $l_{g 2-l} 5$.

\section{CIRCUIT DESIGN}

The distributed optical front-end is based on a GaInAs/InP p-i-n photodiode chip from BT\&D and a full-custom designed MMIC including a

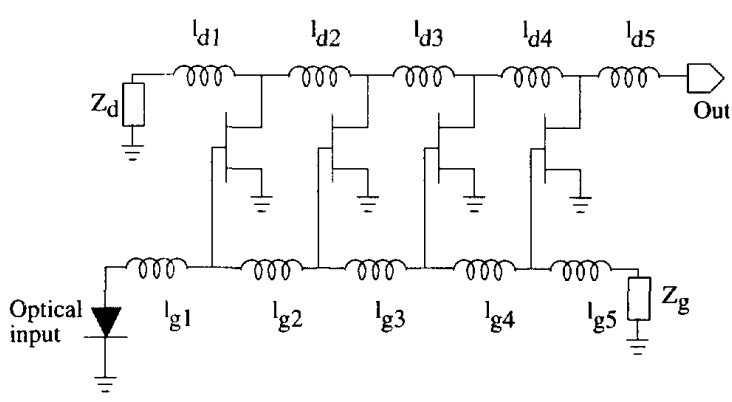

Fig. 2 Simplified schematic of distributed optical front-end amplifier. 
distributed amplifier. The MMIC was realised using a GaAs ion-implanted MESFET process with an $f_{T}$ of $20 \mathrm{GHz}$ from GEC-Marconi. The front-end employs a single photodiode to decrease the parasitic junction capacitance. However, the use of a single photodiode does not remove the laser RIN (Relative Intensity Noise), in contrast to a balanced front-end $[3,5]$, and may reduce the receiver sensitivity. Therefore, a recently proposed fibre Mach-Zehnder interferometer is used to suppress the local oscillator RIN [7]. By using this all optical RIN suppressing interferometer the signal and local oscillator powers are efficiently exploited using a single photodiode front-end. The layout of the designed MMIC is shown in fig. 3 and measures $1.8 \mathrm{~mm}$ by $1.8 \mathrm{~mm}$. The inductances $\lg 2-\lg 5$ were realised as short pieces of microstrip line. The inductances in the artificial drain transmission line, $l_{d} 1-l_{d} 4$, were realised as a combination of spiral inductors and microstrip line. MIM (Metal Insulator Metal) capacitors were used as dc-blocks on-chip, resulting in a low frequency cut-off at $2 \mathrm{GHz}$. The photodiode and the MMIC were bonded on alumina thinfilm substrate into a complete optical front-end.

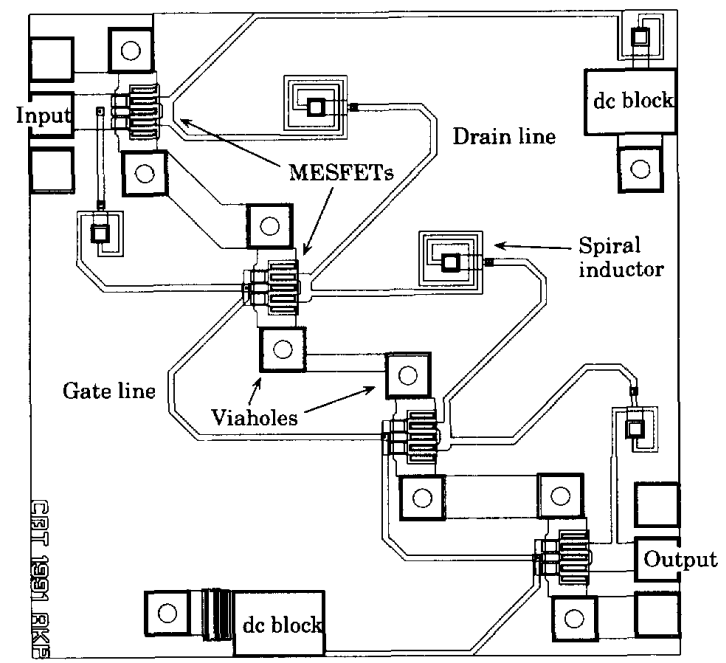

Fig. 3 Layout of the realised distributed amplifier MMIC. The chip measures $1.8 \mathrm{~mm}$ by $1.8 \mathrm{~mm}$.

\section{FRONT-END CHARACTERISATION}

The transimpedance and the equivalent input noise current density were measured using a lightwave test-set HP83420A and a spectrum analyser.

The results of the transimpedance and equivalent input noise current density measurements are shown in fig. 4 together with the simulations. A very good agreement is observed between the measured and simulated transimpedance except for the dip at $9 \mathrm{GHz}$, which was caused by a defective thinfilm resistor in the photodiode bias circuitry.

The average input noise current density is $20 \mathrm{pA} / \sqrt{\mathrm{Hz}}$ within a bandwidth of $3-13 \mathrm{GHz}$, this value is close to previously published results for tuned optical front-ends in the same frequency range [3]. The transimpedance in the same frequency range is in average $38 \mathrm{~dB} \Omega$.

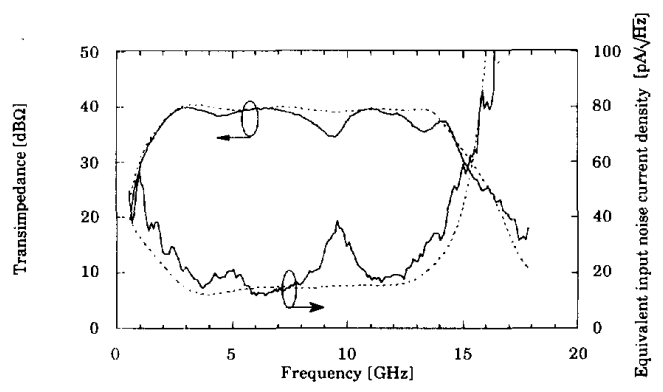

Fig. 4 Measured and simulated transimpedance and equivalent input noise current density of distributed front-end. Solid lines are measurements and dashed lines are simulations.

The different noise contributions in the front-end were simulated to clarify their influence on the total front-end input noise. The total noise was divided into the following sources:

- MESFET noise, $\left\langle i_{\mathrm{FET}}^{2}\right\rangle$.

- Thermal noise from the photodiode including losses in interconnect network between photodiode and the MMIC, $\left\langle i_{\text {diode }}^{2}\right\rangle$. 
- Thermal noise due to losses in the drain transmission line, $\left\langle i_{\text {drain }}^{2}\right\rangle$.

- Thermal noise due to losses in the gate line, $\left\langle i_{\text {gate }}^{2}\right\rangle$.

- Noise from the terminations $\left(Z_{\mathrm{g}}\right.$ and $Z_{\mathrm{d}}$ in fig. 2), $\left\langle i_{\text {term }}^{2}\right\rangle$.

These five contributions are uncorrelated and the total squared input noise current density can be expressed as

$$
\begin{aligned}
& \frac{d\left\langle i_{\text {neq }}^{2}\right\rangle}{d f}= \\
& \quad \frac{d\left\langle i_{\text {FET }}^{2}\right\rangle}{d f}+\frac{d\left\langle i_{\text {diode }}^{2}\right\rangle}{d f}+\frac{d\left\langle i_{\text {drain }}^{2}\right\rangle}{d f}+\frac{d\left\langle i_{\text {gate }}^{2}\right)}{d f}+\frac{d\left\langle i_{\text {term }}^{2}\right\rangle}{d f}
\end{aligned}
$$

Fig. 5 shows the contribution from the five different noise sources in percent of the total noise as function of frequency. As observed from this figure the noise from the FETs is dominating over the entire passband followed by the diode noise. The three remaining noise sources are almost insignificant except for the noise from the terminations which exhibit a peak around $6 \mathrm{GHz}$. Each of the terms has been integrated over the frequency range from $3-13 \mathrm{GHz}$ and listed in table I. From this table we conclude that the dominating noise contribution comes from the FETs, whereas noise from transmission line losses and terminations is negligible. This is in contrast to previous publications where the terminations

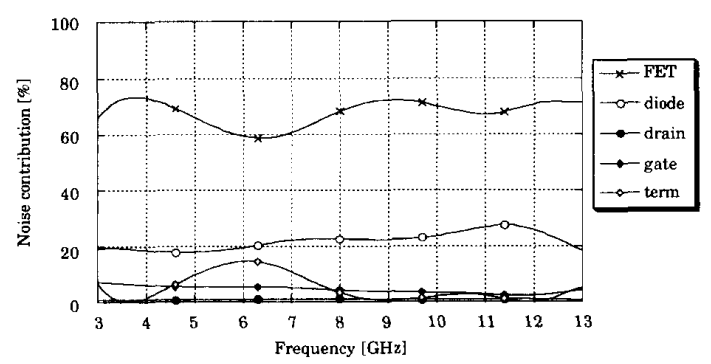

Fig. 5 Simulated noise contribution in percent of the distributed optical front-end.

\begin{tabular}{|l|c|}
\hline Noise source & Contribution \\
\hline MESFETs & $68 \%$ \\
\hline Photodiode & $22 \%$ \\
\hline Drain line & $1 \%$ \\
\hline Gate line & $4 \%$ \\
\hline Terminations & $5 \%$ \\
\hline
\end{tabular}

Table I Simulated noise contributions in distributed front-end. Integrated over 3-13 GHz.

( $Z_{\mathrm{g}}$ and $Z_{\mathrm{d}}$ in fig. 2) have been considered as important noise source in the distributed frontend amplifier, especially at low frequencies [5]. Since a general purpose MESFET foundry process with moderate noise performance was used to realize the MMIC, the FET noise contribution is high. It is therefore possible to decrease the equivalent input noise current in fig. 4 considerably by using FETs with lower noise.

\section{SYSTEM EXPERIMENTS}

The distributed optical front-end was tested in a $2.5 \mathrm{Gbit} / \mathrm{s}$ system set-up as shown in fig. 1 . Two $\lambda / 4$ shifted MQW DFB lasers with a $1.5 \mathrm{MHz}$ linewidth were used as transmitter and local oscillator laser [8]. The CPFSK signal was obtained by directly modulating the transmitter laser with a pattern generator. In addition to the distributed optical front-end commercial microwave amplifiers were used as IF amplifiers and a $7.7-12.9 \mathrm{GHz}$ microstrip filter was used as noise filter. The IF was $10 \mathrm{GHz}$ and a modulation index of 0.8 was used. Two experiments with and without the all-optical Mach-Zehnder RIN suppressor were performed. Fig. 6 shows the measured bit error rate curves for the two experiments. The improvement of $1.5 \mathrm{~dB}$ in receiver sensitivity is in close agreement with expectations when the LO RIN and the LO power are considered [7].

\section{CONCLUSION}

A low-noise optical front-end with a $10 \mathrm{GHz}$ bandwidth has been presented. The front-end 


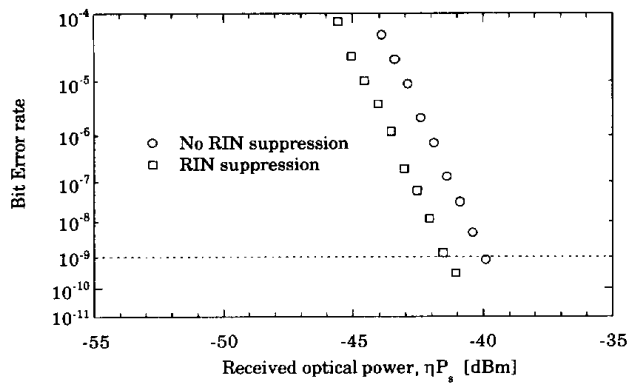

Fig. 6 Measured bit error rate curves at $2.5 \mathrm{Gbit} / \mathrm{s}$ with and without RIN suppression using a $2^{7}-1$ PRBS.

exhibited an average equivalent input noise current density of $20 \mathrm{pA} / \sqrt{\mathrm{Hz}}$ in a $3-13 \mathrm{GHz}$ bandwidth and an average transimpedance of $38 \mathrm{~dB} \Omega$. The noise of the front-end is lower than previously published results for distributed optical front-ends, in spite of the moderate noise performance of the employed MESFETs. The dominating noise source was found to be the FET noise indicating that the noise of the front-end can be further decreased if lower noise FET processes are used, such as HEMT processes. The presented front-end was also tested in a CPFSK system set-up, with an intermediate frequency of $10 \mathrm{GHz}$. A sensitivity as low as $-41.5 \mathrm{dBm}$ at a bit rate of $2.5 \mathrm{Gbit} / \mathrm{s}$ was obtained. To our knowledge this is the best receiver sensitivity obtained with a distributed optical front-end amplifier in a coherent heterodyne receiver at $2.5 \mathrm{Gbit} / \mathrm{s}$.

\section{ACKNOWLEDGEMENTS}

The authors wish to thank Drs. P. Jeppesen and P. Danielsen for valuable discussions and suggestions. Fujitsu Laboratories, Ltd. are gratefully acknowledged for supplying the DFB lasers. This work was financially supported by the Danish Technical Research Council.

\section{REFERENCES}

[1] T. Chikama, T. Naito, G. Kiyonaga, G. Ishikawa and H. Kuwahara

"Optical heterodyne continuous phase FSK transmission experiment up to $4 \mathrm{Gbit} / \mathrm{s}$ "

Proc. 16th ECOC, Amsterdam, Vol. 1, pp. 65-68, 1990.

[2] T. Imai, Y. Ichihashi, N. Okhawa, T. Sugie, Y. Hayashi and $\mathrm{T}$. Ito

"A field experiment in $2.5 \mathrm{Gbit} / \mathrm{s}$ optical coherent transmission through installed submarine trunk-lines" Proc. 16th ECOC, Amsterdam, Vol. 1, pp. 323-326, 1990

[3] F. Ebskamp and R. J. S. Pedersen

"The application of a balanced 6-15 GHz low-noise tuned optical front-end in a 5 Gbit/s CPFSK heterodyne system" Proc. 18th ECOC, Berlin, Vol. 1, pp. 309-312, 1992.

[4] J. L. Gimlett

"A new low noise $16 \mathrm{GHz}$ PIN/HEMT optical receiver"

Proc. 14th ECOC, Brighton, vol. 2, 1988, pp.13-16.

[5] N. Takachio, K. Iwashita, S. Hata, K. Onodera et al. "A 10 Gbit/s optical heterodyne detection experiment using a $23 \mathrm{GHz}$ bandwidth balanced receiver"

Proc. of MTT Symposium, Dallas, Vol. 1 pp. 149-151, 1990.

[6] C. S. Aitchison

"The use of artificial transmission lines in optical external modulators and optical detectors"

Workshop proceedings of European Microwave Conference, Stuttgart, pp. 14-21, 1991.

[7] R. J. S. Pedersen and F. Ebskamp

"New all-optical RIN suppressing, image rejection receiver with efficient use of LO- and signal power"

IEEE Photonics Tech.Lett., Vol. 5, No. 12, December 1993.

[8] Y. Kotaki and H. Ishikawa

"Narrow linewidth and wavelength tunable distributed feedback lasers"

Proc. 2nd International Conference on Indium Phosphide and Related Materials, Denver, pp. 185-188, 1990. 